\title{
Supplementary Material: New statistical quantification of the impact of active deformation on the distribution of submarine channels
}

Marco Pizzi ${ }^{1,2^{*}}$, Alexander C. Whittaker ${ }^{1}$, Lidia Lonergan ${ }^{1}$, Mike Mayall ${ }^{1}$, W. Hamish Mitchell ${ }^{1}$.

${ }^{1}$ Department of Earth Science \& Engineering, Imperial College, South Kensington, London SW7 2AZ, UK

${ }^{2}$ now at: Fugro GB Marine Limited, Victory House, Trafalgar Wharf (Unit 16), Hamilton Road, Portsmouth, PO6 4PX, UK

\section{Previous Work}

This document provides additional descriptions of the study area, methods and analyses outlined in the main manuscript. The study area on the Southern Lobe of the Niger Delta (Figure 1, main manuscript) has recently been the subject of several published works using 3D seismic reflection data (e.g. Jolly et al., 2016 and 2017; Mitchell et al., 2020) that have addressed the structural evolution of the region and its implications for the geomorphology, behaviour and architectures of deep-water systems. These previous studies have addressed a range of time intervals within the stratigraphy from the early Miocene to the Holocene (Table S1). This manuscript relies on the detailed quantification of strain and strain rate for the fold and thrust belt as reported in Pizzi et al. 2020; and mapping of deepwater channel systems reported in Pizzi (2019).

Table S1: Detail of the time intervals investigated by previous studies in the same study area compared to the present work.

\begin{tabular}{|c|c|c|c|c|}
\hline Time intervals & $\begin{array}{l}\text { Jolly et al. (2016, 2017) } \\
\text { and Mitchell et al. } \\
(2020)\end{array}$ & Pizzi (2019) - PhD & Pizzi et al. (2020) & This study \\
\hline 3.7 Ma to Present & & & & Not investigated \\
\hline 5.5 to $3.7 \mathrm{Ma}$ & \multirow{8}{*}{$\begin{array}{l}\text { Units not defined but } \\
\text { strain evolution on some } \\
\text { faults quantified. }\end{array}$} & Unit 1 & \multirow{3}{*}{$\begin{array}{l}\text { Units } 1 \text { to } 3 \text { not } \\
\text { subdivided }\end{array}$} & Unit 1 \\
\hline 6.5 to $5.5 \mathrm{Ma}$ & & Unit 2 & & Unit 2 \\
\hline 7.4 to $6.5 \mathrm{Ma}$ & & Unit 3 & & Unit 3 \\
\hline 9.5 to $7.4 \mathrm{Ma}$ & & Unit 4 & & Unit 4 \\
\hline 12.8 to $9.5 \mathrm{Ma}$ & & Unit 5 & & Unit 5 \\
\hline 15 to $12.8 \mathrm{Ma}$ & & Unit 6 & & Unit 6 \\
\hline 23.2 to $15 \mathrm{Ma}$ & & & \multirow[b]{2}{*}{ Not investigated } & \multirow[b]{2}{*}{ Not investigated } \\
\hline $\begin{array}{l}\text { Base Agbada to } 23.2 \\
\text { Мa }\end{array}$ & & & & \\
\hline
\end{tabular}




\section{Study area and structural evolution}

These studies have enabled the structural evolution of eleven thrust-folds on the lower slope of the southern lobe of the Niger Delta (thrusts labelled 12 to 22 in Fig. 2 and Fig. S1) to be quantified in exceptional detail (Pizzi, 2019; Pizzi et al., 2020). Deformation in this area started before 15 Ma and the development of the fold and thrust belt until 3.7 Ma has been described both qualitatively and quantitatively from the mapping of multiple seismic horizons, from which six time windows have been identified (Table S1, Fig. S1). As described in Pizzi et al. (2020), the horizons were calibrated with age data provided by Shell from an unpublished well in the area and from published data in Krueger and Grant (2011). We use these as the tectonic template for this study. Strain and strain rates were calculated using a modified version of the line-length balancing technique following the methodology described in Jolly et al. (2016) and improved further by Pizzi et al. (2020). This methodology included the measure of shortening and strain of both the faulted and folded horizons to allow deformation to be consistently quantified beyond and above the tip of blind thrusts. Strain and shortening rates for the thrust-folds found within the central area were reconstructed by projecting the horizons across the scarp and over the structure while maintaining the overall shape of the structure (Jolly et al., 2016). The reader is referred to Pizzi et al., (2020) for a full description of the structural evolution and the strain analyses used in this approach. Strain rates were used to show thrust activity per time interval. An example of a strain rate map is given for the time interval from 5.5 to 3.7 Ma in Figure 2C; strain rates for all the intervals are presented in section 3 of the supplementary material (c.f. Pizzi 2019; Pizzi et al., 2020). The strain rates in the manuscript reflect a normalised line length of $7 \mathrm{~km}$ meaning that a strain rate of 3\%/Ma reflects a horizontal shortening rate of ca. $210 \mathrm{~m} / \mathrm{Ma}$ (Pizzi et al., 2020). 


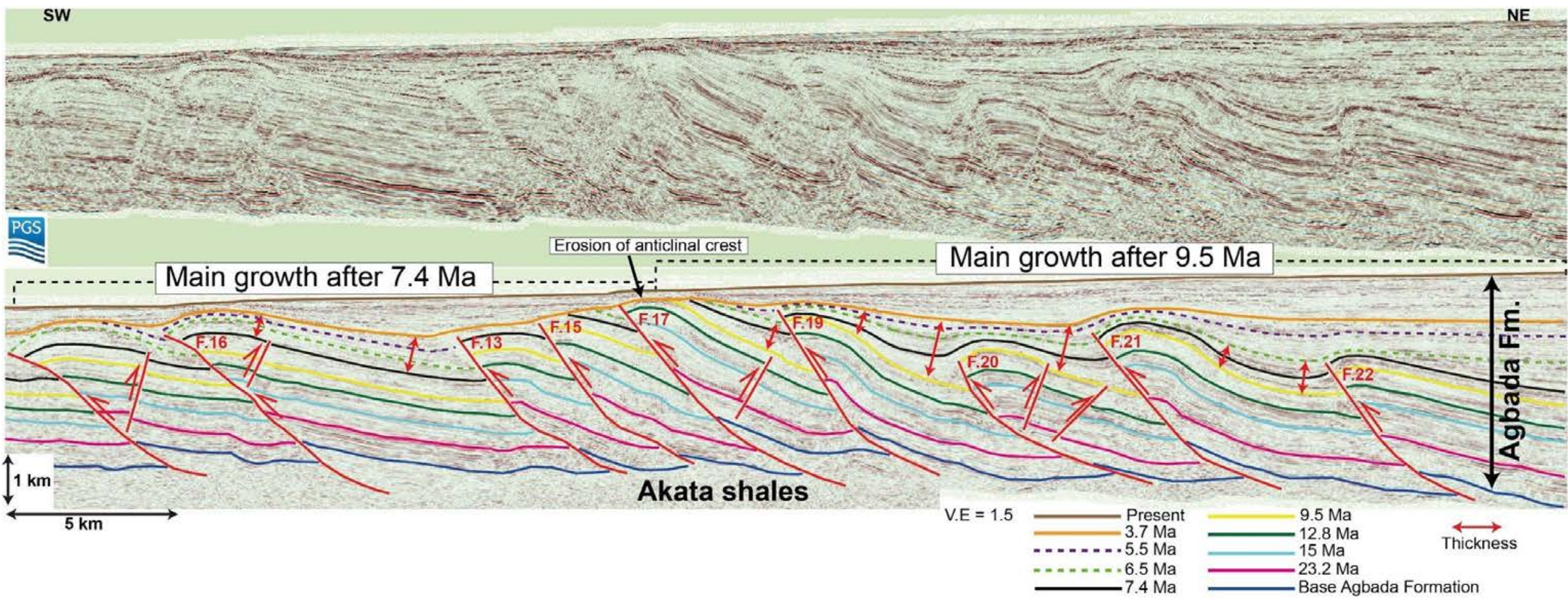

Figure S1: Uninterpreted and interpreted seismic section through the study area (located on Fig. 2A), and adapted from Pizzi et al., 2020. This study focuses on the interval between 15 and 3.7 Ma, while the individual growth history of each thrust-fold until the present day is given in Pizzi et al., (2020). Slope channels were identified, and their distribution tracked, through a series of seismic amplitude maps extracted from each interval between 15 and $3.7 \mathrm{Ma}$. 


\section{Identification and mapping of submarine channels}

Deep-water slope channels were identified within each of the six units, described by Pizzi (2019), using standard seismic stratigraphic techniques. RMS (root-mean-square) seismic amplitudes were extracted from each unit, through multiple isoproportional slices providing high level of detail even within a single unit. The location of channels was carefully interpreted from the RMS extractions and an example is given in Fig. S2 for the 5.5 to $3.7 \mathrm{Ma}$ interval. From these, the spatial distribution of submarine channel systems at any one-time interval and how they evolved with time were derived and mapped. Sections through the seismic reflection data (such as the examples shown in Figures S3, S4, S5) confirmed the presence of such channels and further helped to distinguish between different facies and architectures. For a full discussion of the seismic imaging, and the associated facies and architectures, the reader is referred to Pizzi (2019).

In a few cases, the imaged submarine channels were not always tracked completely across the study area or on both sides of a specific fault, either because of the degraded seismic quality, intense deformation or due to the erosion of stratigraphy over the crests of anticlines (Figures S2, S3). These issues are locally more pronounced in the centre of the fold belt after the 7.4 Ma horizon and, as a result, channels were mapped with high degree of confidence updip and downdip of this central zone, but often without a direct link between the two because of the gaps in the centre of the fold belt. In these circumstances, the correlation between submarine channels in the inner and outer zones was established based on the stratigraphic level where they were foundwhich is why we present the data in time intervals for our statistical analysis. Channel crossings that were not specifically imaged or identified are not included in the statistical compilation. The only exception is found in the 5.5 to 3.7 Ma interval where the existence of one channel crossing a high strain-rate segment of a fault was inferred with a high degree of confidence in the centre of the fold belt (Fig S2). 


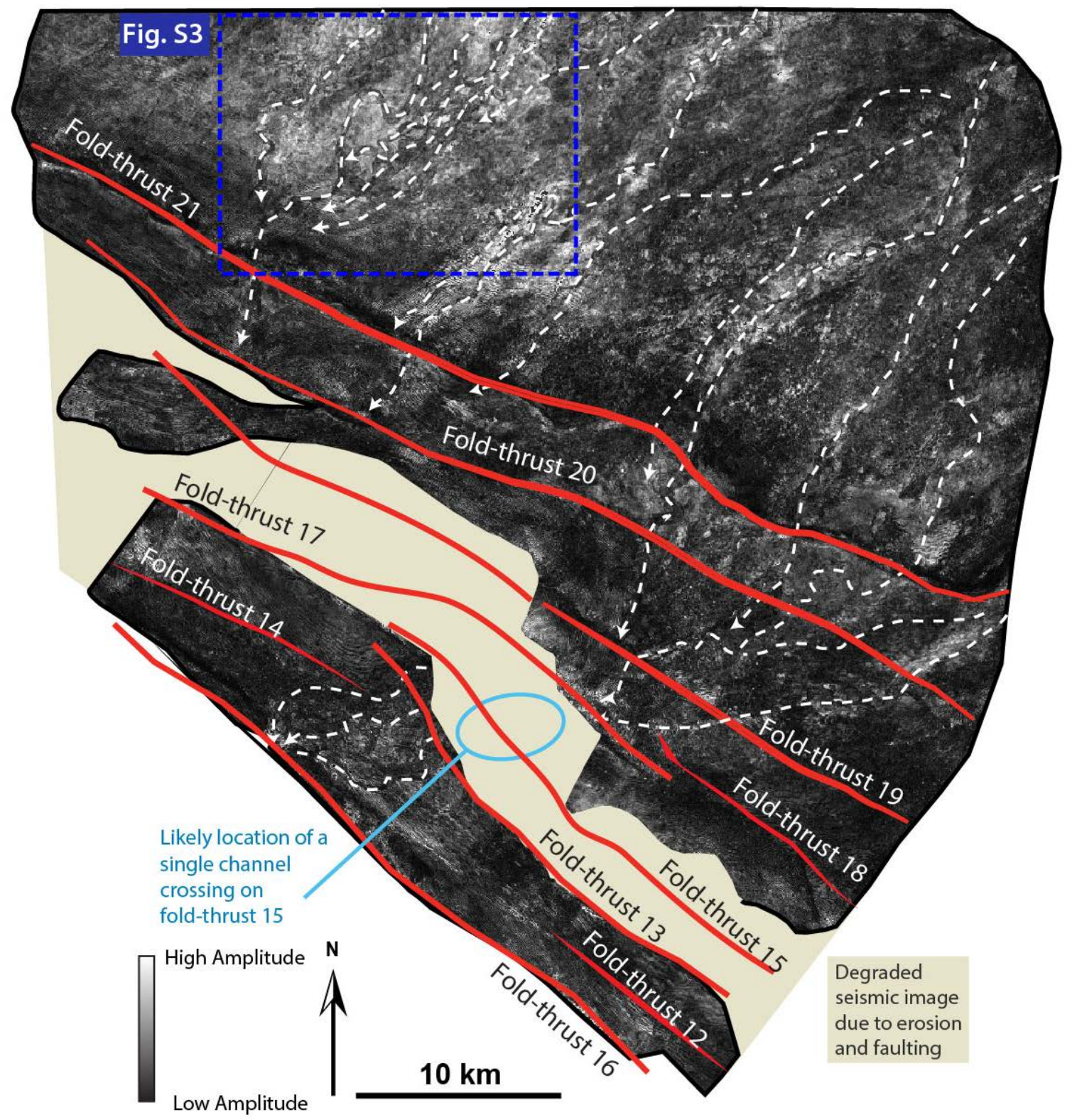

Figure S2 Example of channel identification adapted from Pizzi, 2019. RMS amplitude extraction within the 5.5 to $3.7 \mathrm{Ma}$ interval.The amplitude extractionclearly shows sinuous channel forms crossing the study area by interacting with intervening faults. The channels pathways and their routing systems are digitized and mapped to highlight their spatial distribution at this time. One channel crossing of fault 15 is inferred to have occurred in the relay zone between faults 13,15 and 17 . Variable 
facies architectures were identified and discussed in Pizzi (2019). Parts of the amplitude extraction are further shown in figure S3 (Modified from Pizzi, 2019).

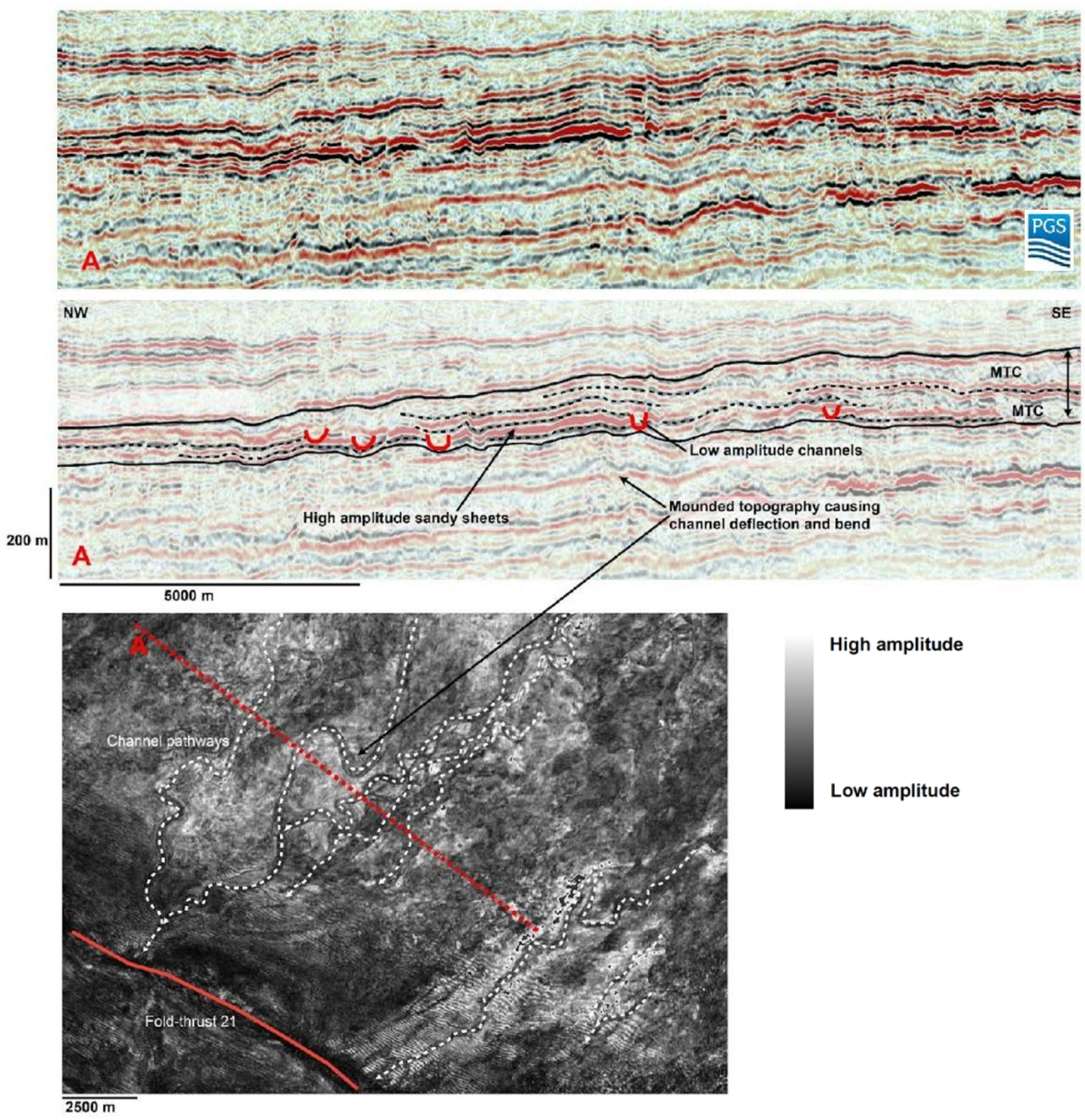

Figure S3: Enlargement of part of Figure S2, showing channel systems as identified by both RMS amplitude extractions and seismic reflection data, adapted from Pizzi, 2019. Upper panel: expression of the channel systems in the seismic data along line $A$, the position of which is depicted in the lower panel. Red solid lines depict channels identified upstream of fold-thrust 21. Lower panel RMS amplitude extraction - white dashed lines show channel pathways in plan view. 


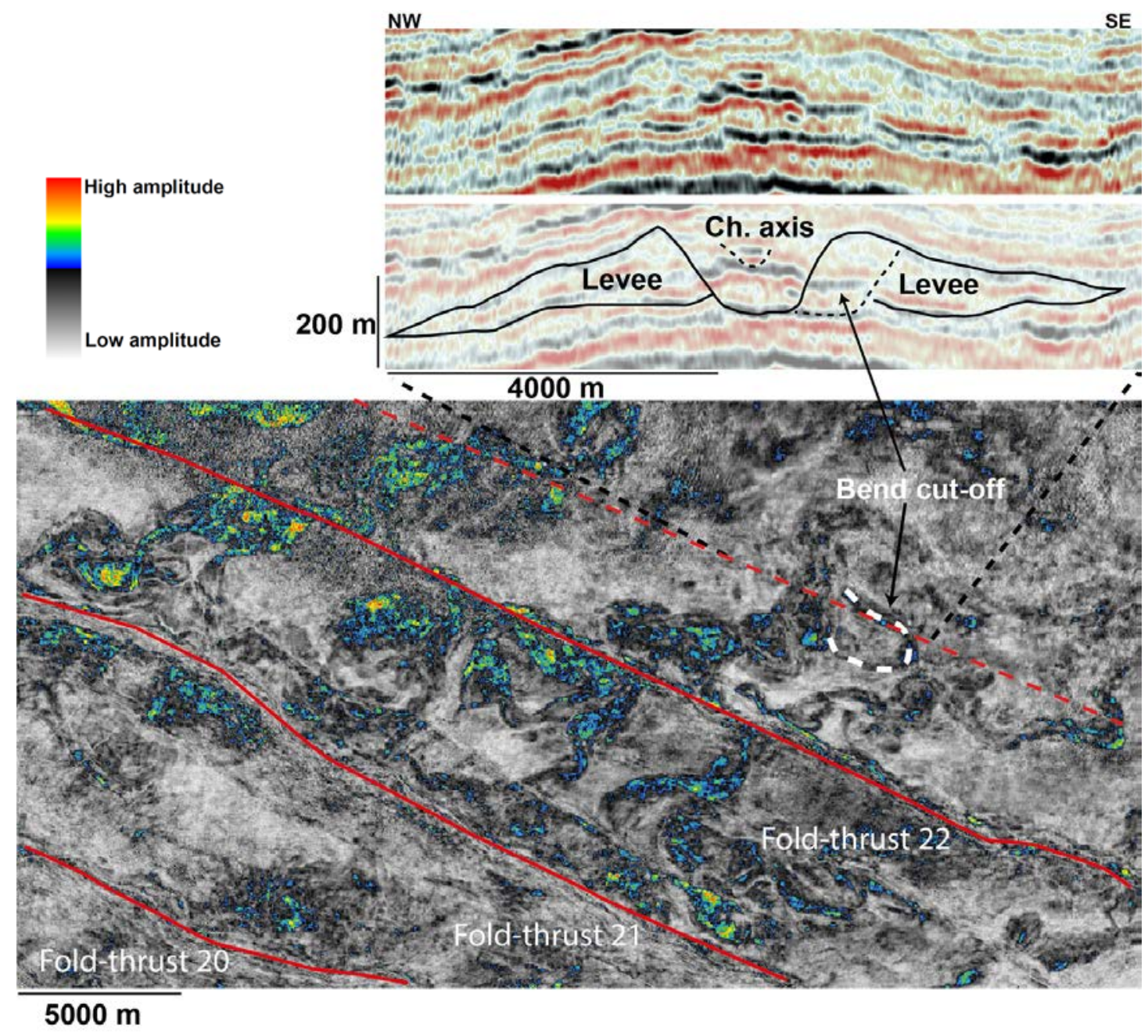

Figure S4: Seismic expression of the channels: Examples of leveed channels from the 12.8 to $9.5 \mathrm{Ma}$ interval in both section (upper panel) and plan view (lower panel), adapted from Pizzi, 2019. 


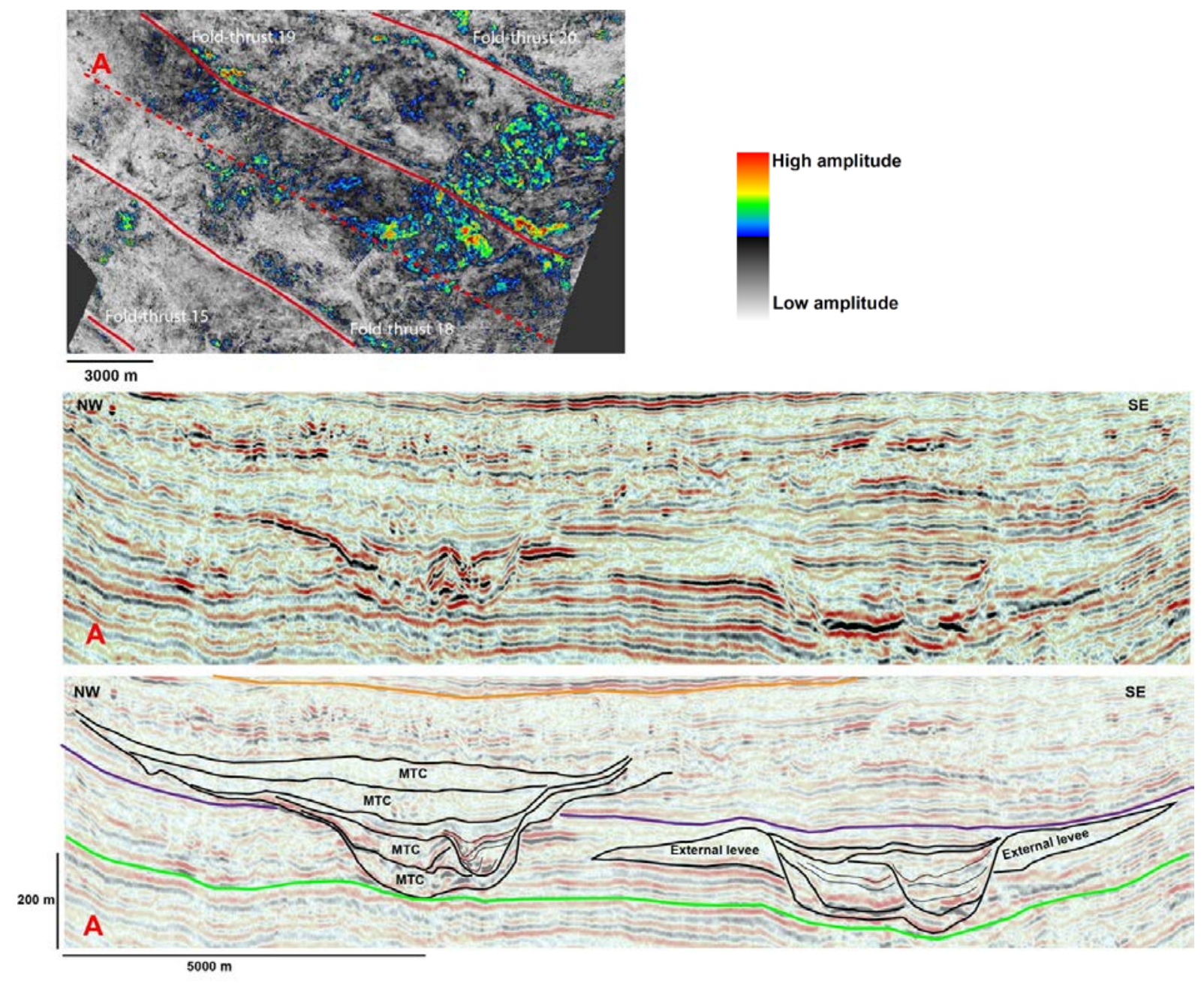

Figure S5: Examples of channels from the 6.5 to 5.5 Ma interval in both section (upper panel) and plan view (lower panel), adapted from Pizzi, 2019. MTC represents mass transport complexes, which are not discussed further in this paper.

For each time interval (units 6 to 1; Table S1), palaeogeographic maps showing the locations of submarine channel systems were derived from the seismic mapping. These were overlain onto their corresponding fault strain rate map, taken from Pizzi et al., (2020) and (Pizzi, 2019) to evaluate the relationships between the structures and the distribution of deep-water sedimentary systems (Fig. S6). All visible channels and associated crossings in the period between 15 and $3.7 \mathrm{Ma}$, and their corresponding fault strain rates were documented, noting that a single channel may cross multiple structures; the full data for each time interval used to construct the frequency distributions in Figure 3 of the main text are shown in Fig. S6. Where channels cross a fault segment that was not active in the 
time slice analysed, but was active before or after, it is recorded as a zero-strain rate crossing. These channels crossings are shown as black circles in Fig. S6.

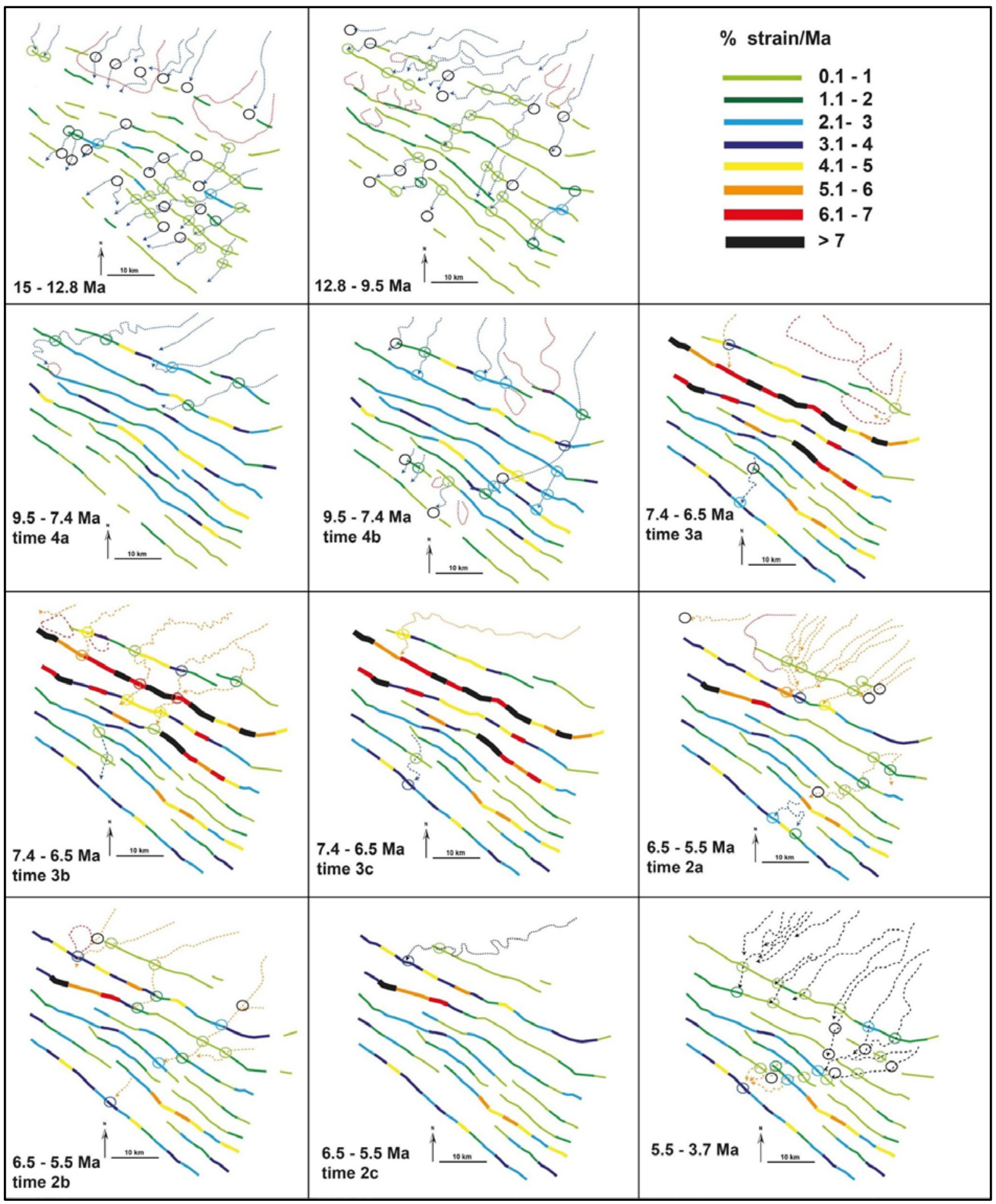

Figure S6: Slope channels interacting and crossing the evolving fault network during the entire period of study from 15 to 3.7 $\mathrm{Ma}$ (including the time slices internal to a single unit). Note that 173 crossing points (circles) have been recorded for the entire period of study. Black circles represent crossing of a fault segment that was inactive at that particular time. For Units 2, 3 and 4, two or three time slices are required to show all the channels in that interval and are depicted accordingly 


\section{Statistical Data Analysis}

Histograms and cumulative density functions (Figure 3, main manuscript) were derived of the magnitude of strain rate recorded at each channel-fault intersection for each of the six time intervals described above and for the entire period of activity from 15 Ma to 3.7 Ma. The mean strain rate for a channel-fault intersection in each time interval was also recorded. To produce a robust measure of strain rate within the fault array of the whole, with which the channel-fault intersection data could be compared, we need to compile distributions of the cumulative length of active fault segments, deforming at a given strain rate for each time interval and for the entire period of study. This enabled us to work out the typical strain rate within the fault array at each interval. We note that the maximum length of all the faults in the array for any one time was $417 \mathrm{~km}$. The results from each unit were subsequently summed and normalized to derive three cumulative density functions (Figure 3); one of the number of channel crossing points, and two depicting cumulative distribution of fault segment lengths, with and without segments of zero strain which were subsequently or previously active; all three were compiled as a function of strain rate. As we had not measured all possible submarine channels on the southern lobe of the Niger Delta, we compared the distributions statistically to test the hypothesis that the channel crossing points preferentially exploited locations of lower strain rate in the evolving fault array. To do this, we used a standard two sample Kolmogorov-Smirnov test (K-S test) to test whether two underlying one-dimensional probability distributions differ. It quantifies a distance (Dmax) between the empirical cumulative distribution functions of two samples. The null hypothesis is rejected (meaning the distributions are statistically different) if:

$$
\operatorname{Dmax}>c(\alpha) \sqrt{\frac{n+m}{n m}}=\text { Dcrit }
$$

Where $n=\mathrm{km}$ of active faults, $m=$ number of channel crossings, Dcrit = critical distance above which the null hypothesis is rejected, and $c(\alpha)=$ confidence interval as described in Table S2.

Table S2: Values for $\mathrm{c}(\alpha)$ at different confidence intervals

\begin{tabular}{|l|l|l|l|l|}
\hline Confidence interval, $\alpha$ & $0.1(90 \%)$ & $0.05(95 \%)$ & $0.01(99 \%)$ & $0.001(99.9 \%)$ \\
\hline$c(\alpha)$ & 1.07 & 1.36 & 1.62 & 1.95 \\
\hline
\end{tabular}

The total number of channel crossing points over the period of study, $m$, was 173 . The $\mathrm{km}$ of active fault segments ( $n$ ) was derived as the sum of the number of kilometres of active fault segments during each of the six time-intervals, and equals $2505 \mathrm{~km}$ (or $2139 \mathrm{~km}$ if segments of zero-strain are excluded from the count for each time interval). These values are listed in Table S3.

The null hypothesis (i.e. that the distribution of strain rates at channel crossing points is the same as the distribution of fault segment strain rates) was tested at the $95 \%$ confidence interval as a standard 
measure of whether the distributions were different. We also tested the null hypothesis at the $\quad 99.9 \%$ confidence interval as a rigorous upper limit. The values used to construct the histograms, cumulative distributions and channel crossing evolution over time, and our statistical analysis shown in Figures 3 and 4 of the main manuscript are presented in Table S3. We perform the K-S test for channel crossings at the scale of the whole fault array rather than on individual or groups of structures across strike to avoid arbitrary grouping of data that may pre-determine the results and to obtain a statistically valid sample sizes. 
Table S3: Statistical parameters used to construct the histograms and normalized distributions for the K-S test. Note that Dcrit is 0.11 and 0.15 for $95 \%$ and $99.9 \%$ confidence interval, respectively. Also note that the minimum measured Dmax is 0.16 , which is above Dcrit even at $99.9 \%$ confidence interval. Therefore, the null hypothesis is rejected.

\begin{tabular}{|c|c|c|c|c|c|c|c|c|}
\hline \multicolumn{3}{|c|}{ Histograms } & \multicolumn{6}{|l|}{ Cumulative distributions } \\
\hline \multirow[b]{2}{*}{$\begin{array}{l}\text { Strain } \\
\text { rate } \\
\text { category } \\
\text { (\%/Ma) }\end{array}$} & \multirow[b]{2}{*}{$\begin{array}{l}\text { Channel } \\
\text { crossing } \\
\mathrm{s}(n)\end{array}$} & \multirow[b]{2}{*}{$\begin{array}{l}\text { Faults }(\mathrm{km}, \\
m)\end{array}$} & \multirow{2}{*}{\multicolumn{2}{|c|}{\begin{tabular}{|l|l|l|}
$\begin{array}{l}\text { Cumulative strain rate } \\
(\% / \mathrm{Ma})\end{array}$ & $\begin{array}{l}\text { Cumulative } \\
\text { channel } \\
\text { crossings } \\
\text { (normalized) }\end{array}$ \\
\end{tabular}}} & \multirow[b]{2}{*}{$\begin{array}{l}\text { Column B } \\
\text { Cumulative km } \\
\text { Faults with zero } \\
\text { strain segments } \\
\text { (normalized) }\end{array}$} & \multirow[b]{2}{*}{\begin{tabular}{|l|}
\multicolumn{2}{|l|}{ Column C } \\
Cumulative km \\
Faults without \\
zero strain \\
segments \\
(normalized) \\
\end{tabular}} & \multirow[b]{2}{*}{$\begin{array}{l}\text { Absolute } \\
\text { difference } \\
\text { between columns } \\
\text { A-B } \\
\text { (Normalized) }\end{array}$} & \multirow[b]{2}{*}{$\begin{array}{l}\text { Absolute } \\
\text { difference } \\
\text { between columns } \\
\text { A-C } \\
\text { (Normalized) }\end{array}$} \\
\hline & & & & & & & & \\
\hline 0 & 48 & $366(0)$ & 0 & $0(0)$ & $0(0)$ & $0(0)$ & 0 & 0 \\
\hline $0-1$ & 64 & 847 & 0.1 & $48(0.28)$ & $366(0.15)$ & $0(0)$ & 0.13 & 0.28 \\
\hline $1-2$ & 24 & 434 & 1 & $112(065)$ & $1212(0.48)$ & $847(0.40)$ & 0.16 & 0.25 \\
\hline $2-3$ & 18 & 398 & 2 & $136(0.79)$ & $1647(0.66)$ & $1281(0.60)$ & 0.13 & 0.19 \\
\hline $3-4$ & 9 & 197 & 3 & $154(0.89)$ & $2044(0.82)$ & $1679(0.78)$ & 0.07 & 0.11 \\
\hline $4-5$ & 6 & 139 & 4 & $163(0.94)$ & $2241(0.89)$ & $1876(0.88)$ & 0.05 & 0.06 \\
\hline $5-6$ & 2 & 53 & 5 & $169(0.98)$ & $2380(0.95)$ & $2015(0.94)$ & 0.03 & 0.04 \\
\hline $6-7$ & 2 & 36 & 6 & $171(0.99)$ & $2433(0.97)$ & $2068(0.97)$ & 0.02 & 0.02 \\
\hline$>7$ & 0 & 35 & 7 & $173(1)$ & 2470 (0.99) & 2104 (0.98) & 0.01 & 0.02 \\
\hline Total & 173 & $\begin{array}{l}2505 \text { (2139 if } \\
\text { zero strain } \\
\text { rate segments } \\
\text { excluded) }\end{array}$ & $>7(8)$ & $173(1)$ & $2505(1)$ & $2139(1)$ & 0 & 0 \\
\hline & & & \multicolumn{4}{|c|}{ Max absolute difference (Dmax) } & 0.16 & 0.28 \\
\hline & & & \multicolumn{4}{|c|}{ Critical distance (Dcrit) for $\alpha=0.05$, and $c(\alpha)=1.36$ (95\% confidence) } & 0.11 & 0.11 \\
\hline & & & \multicolumn{4}{|c|}{ Critical distance (Dcrit) for $\alpha=0.001$, and $c(\alpha)=1.95$ (99.9\% confidence) } & 0.15 & 0.15 \\
\hline
\end{tabular}

